\title{
THE CONCEPT OF A FULL SCALE FATIGUE TEST OF A SU-22 FIGHTER BOMBER
}

\author{
Piotr Reymer \\ Andrzej Leski \\ Wojciech Zieliński \\ Krzysztof Jankowski
}

Air Force Institute of Technology, ul. Księcia Bolesława 6, 01-494 Warsaw, Poland

piotr.reymer@itwl.pl, andrzej.leski@itwl.pl, wojciech.zielinski@itwl.pl, krzysztof.jankowski@itwl.pl

\begin{abstract}
This article presents a concept of the full scale fatigue test of a Su-22 fighter bomber. The authors define the general concept and goals of the test as well as the tasks to be accomplished in the preparation stage. The current work status is summarized and future tasks are defined.
\end{abstract}

Keywords: full scale fatigue test, Su-22 fighter bomber, life extension program

\section{INTRODUCTION}

\section{Life extension program}

The Su-22 fighter-bomber is a military aircraft used in the Polish Air Force since the mid1980's. According to the decision of the Polish Ministry of Defense the assumed service time for this type of aircraft will be prolonged. Due to the fact that a number of aircraft are nearing the end of the service life guaranteed by the manufacturer, the actual service life adequate to the flight profile in the Polish Air Force, has to be validated. Therefore, the Full Scale Fatigue Test has to be carried out.

The service life of Su-22 fighter bombers is expressed by the cumulated number of flight hours and landings. Therefore, in order to extend service life it is crucial to define new numbers of flight hours and landings and then to validate them in order to assure safe operation within defined intervals.

\section{Technical data}

The Su-22 is a military fighter bomber. There are two versions used in the Polish Air Force, a single-seated fighter and a two-seated trainer. All aircraft are located in the $21^{\text {st }}$ Tactical Air Base in Świdwin. The basic technical parameters of the aircraft are given in Table 1 while the general view of the structure is shown in Figure 1. 
Table 1. Basic technical parameters

\begin{tabular}{|c|c|c|}
\hline Parameter & Value & Unit \\
\hline Maximum takeoff weight & 19500 & {$[\mathrm{~kg}]$} \\
\hline Standard flight weight & $14000 \div 15000$ & {$[\mathrm{~kg}]$} \\
\hline Length & 18.7 & {$[\mathrm{~m}]$} \\
\hline Wing span & $10 \div 13.8$ & {$[\mathrm{~m}]$} \\
\hline Wing area & $34.15 \div 38.49$ & {$\left[\mathrm{~m}^{2}\right]$} \\
\hline Cruising speed & 950 & {$[\mathrm{~km} / \mathrm{h}]$} \\
\hline
\end{tabular}

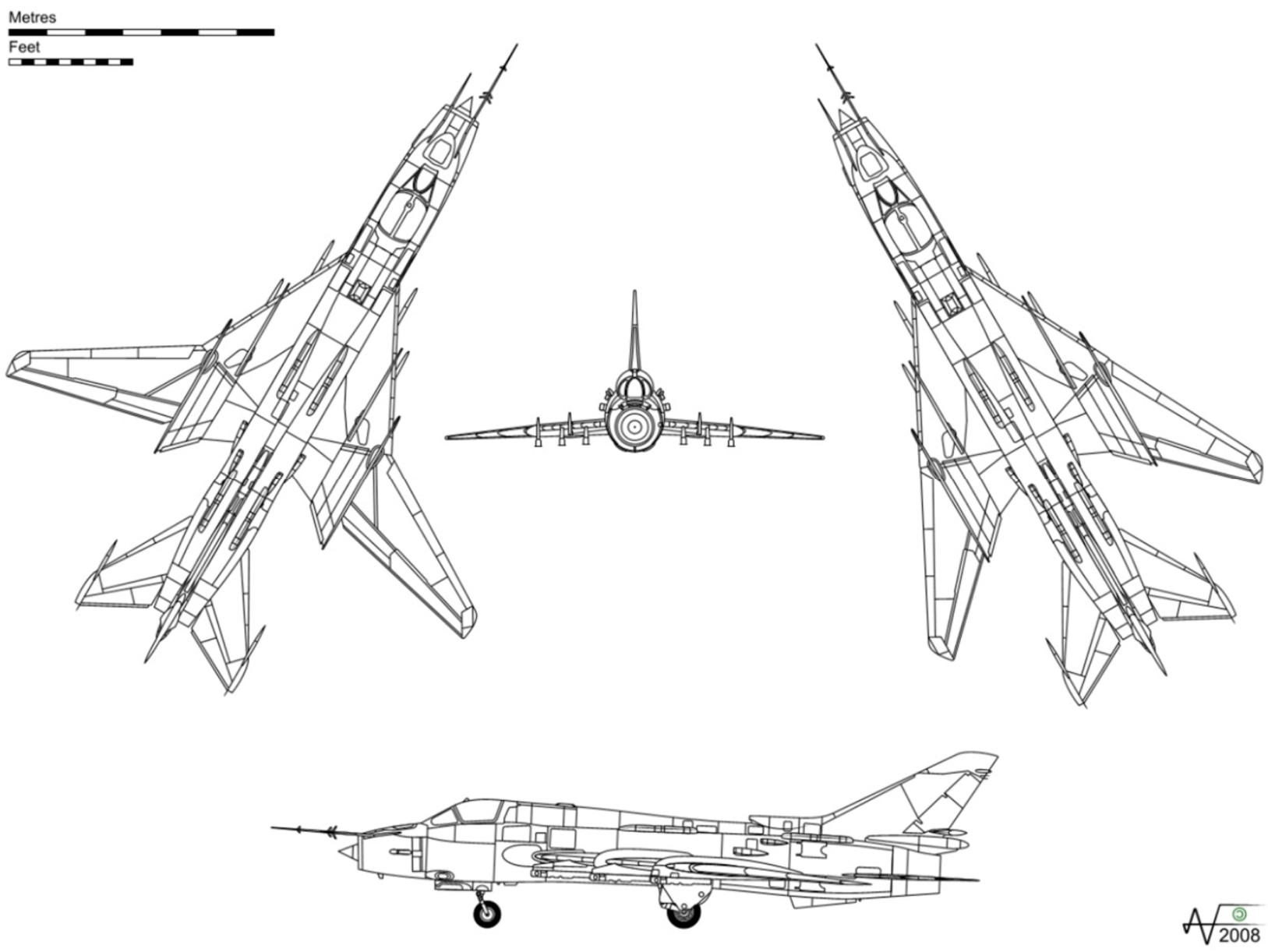

Fig. 1. General view of the Su-22 aircraft with two sweep wing settings

The most significant feature of the Su-22 is the variable sweep wing, which can be set during take-off and landing, subsonic flights and supersonic flights, to 30, 45 or 63 degrees respectively. Since, according to the initial flight profile analysis, the supersonic flights take a maximum of $1 \%$ of the whole flight time, the 63 degrees angle will be neglected during the test.

Nevertheless, since the main goals of the fatigue test include the verification of the number of landings and flight hours, the test will have to be carried out in more than one configuration, which causes additional complications both in terms of the load spectrum definition and design of the test rig. 


\section{TEST GOALS AND ASSUMPTIONS}

The aim of the FSFT is to validate the assumed number of flight hours $(3,200)$ and landings $(6,000)$. The test will be carried out on a withdrawn from service Su-22 UM3K. The total number of flight hours accumulated by the selected aircraft is 1,583 while the total number of landings is 3127.

The load spectrum for the test will be defined both from gathered flight data records (FDR) and, to be carried out, Operational Load Monitoring (OLM) program. Based on the previous experience, the test specimen will be instrumented with a set of 40 strain gauges identical to a strain measurement system installed on the test flight specimen. Since no damage growth history is considered, a block load spectrum will be used (instead of a complex load-by-load spectrum), making it possible to reduce the test duration considerably.

During the test the durability of the below listed structural elements will be proven:

- wing-fuselage attachment points,

- main landing gear attachment points,

- pivot joint of the sweep wing part,

- variable-sweep and fixed wing spars,

- fuselage middle section where the wings are attached,

- wing flaps (inner and outer).

Upon the completion of the test the structure will be examined using NDI techniques. Moreover, two detailed inspections will be carried out during the first stage of the test.

\section{TEST CONCEPT}

The test will be divided into three stages. The first stage will be focused on landing and taxing loads. The loads will be exerted both on the main and front landing gears as well as on the wings and the fuselage. The variable wing sweep will be set to $30^{\circ}$ as for take-off and landing.

In the second stage, the configuration of the aircraft will be changed, including changing the wing sweep angle to $45^{\circ}$ and retracting the main landing gear in order to allow the fixed wing clamp to be mounted.

The last stage will be focused on the wing flaps. The whole aircraft structure will be fixed and will serve only as an interface for the flaps, which will be fully extended and blocked. Loads will be exerted from beneath by means of four hydraulic actuators, one for each flap.

The test rig will be designed as a modular system from standardized elements. The main structure of the test rig will create a rigid base for adaptations of load actuators, balancing and reactions considering the specific geometry of the test article and positions of the load application points.

It is assumed to place the actuators beneath the structure and to exert the forces by means of pushing. This would make it possible to minimize the size of clamps used and, consequently, simplify the whole loading system.

As forces exerted on the variable sweep wing and the front/middle/rear fuselage sections will be acting synchronically, they can be grouped by means of wiffle trees. 


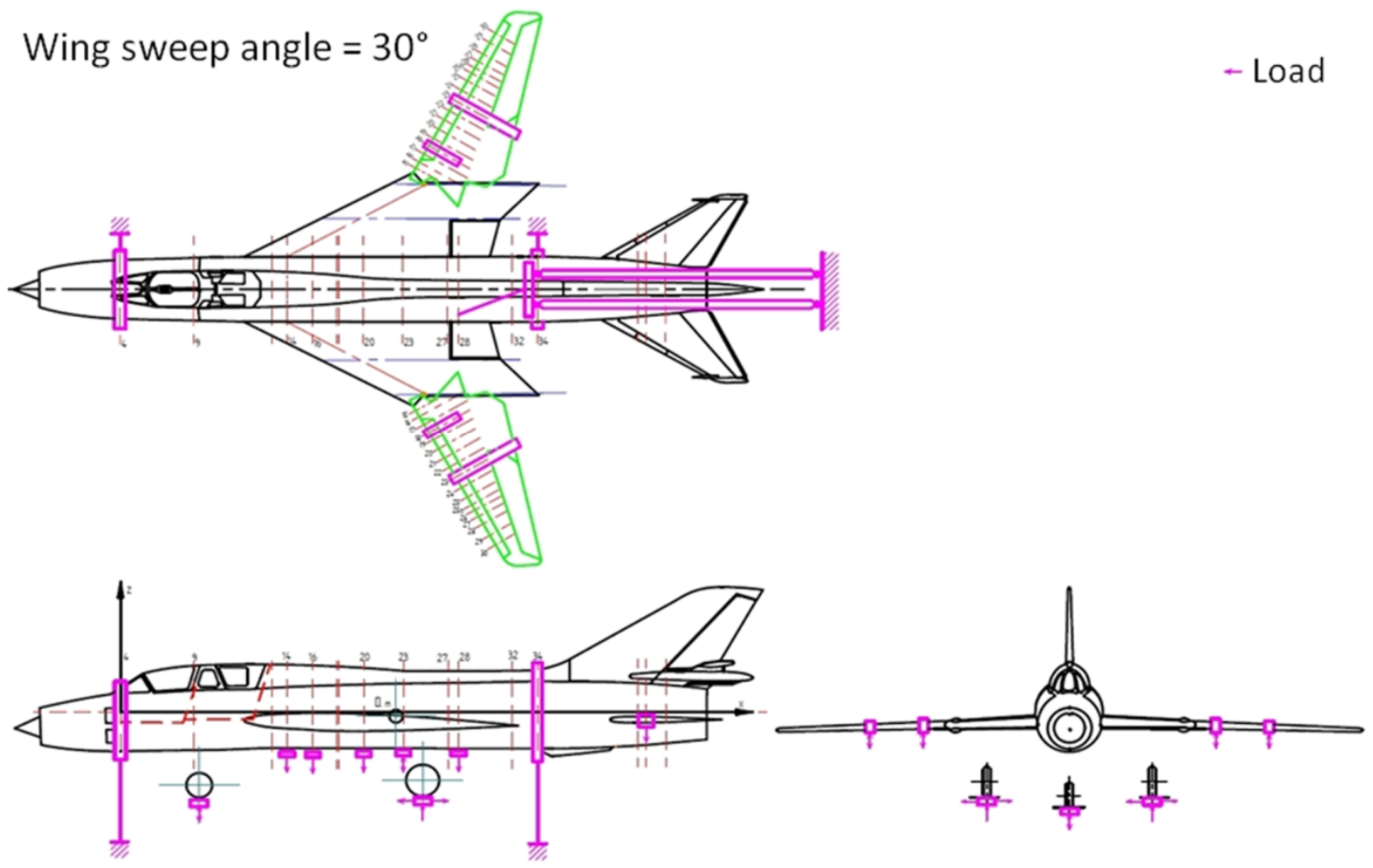

Fig. 2. Test configuration in landing loads stage

In the first stage, simulating landing loads and taxing, the wing sweep will be set to 30 degrees and the structure will be loaded by means of actuators:

- two actuators will be located symmetrically at the variable sweep angle wing part (one per either side of the wing, on the wing rib 18 or 23),

- each main landing gear will be equipped with a set of three actuators acting along $\mathrm{X}, \mathrm{Y}$ and $\mathrm{Z}$ axis.

The structure has to be constrained in the following sections by means of the fixing points with load cells and additional actuators:

- front fuselage section on frame 4 (fixing point with load cell),

- front landing gear tension/compression actuator,

- middle section by means of actuators connected to the hardpoints located in the lower part of frames 14, 16, 20, 23 and 28, attached to the structure by pylon attachments,

- rear fuselage section on frame 34 and horizontal stabilizer pivots (frame 43), engine dummy mount connected to the structure using the existing engine mounts located between frames 28 and 34 inside the engine duct. 


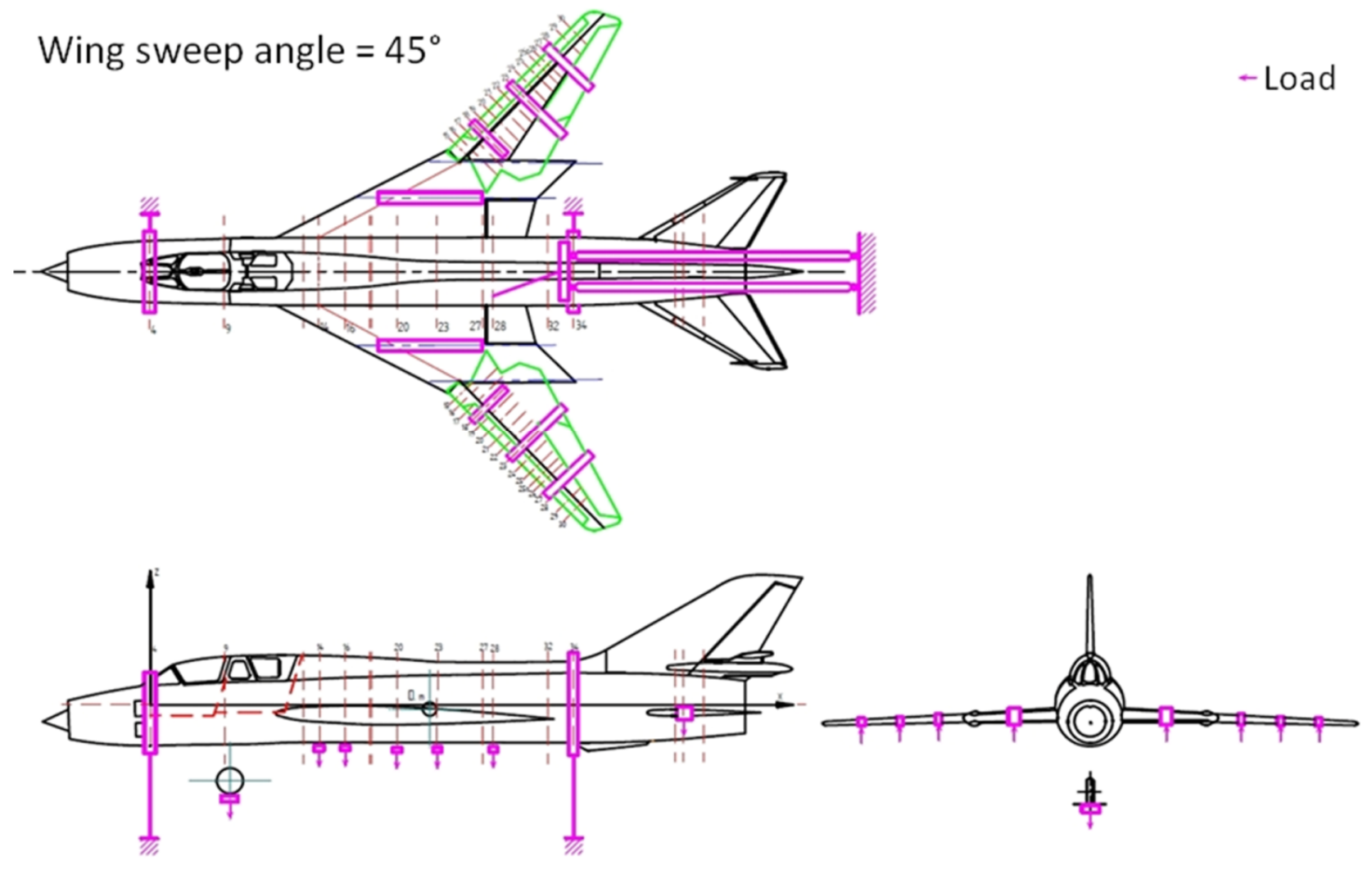

Fig. 3. Test configuration in the flight loads stage

In the second stage, simulating flight loads, the wing sweep will be set to 45 degrees. The main landing gear actuators will be disassembled and the main landing gear will be retracted allowing the fixed wing part clamp to be attached. The structure will be loaded by means of hydraulic actuators:

- maximum of six actuators (maximum of 3 on either side) will be located symmetrically at the variable sweep angle wing part (on the wing ribs 18, 23 and between 27 and 28); if wiffle trees are applied, only one actuator per wing side is sufficient,

- two actuators will be located symmetrically loading the fixed wing part from beneath.

The structure has to be constrained in the following sections by means of fixing points with load cells or additional actuators:

- front fuselage section on frame 4 and front landing gear (frame 9),

- it is permissible to detach the front landing gear and to mount the actuator to the front landing gear mounting axis,

- middle section by means of actuators located on frames $14,16,20,23,28$, attached to the structure by pylon attachments,

- rear fuselage section on frame 34 and horizontal stabilizer pivots (frame 43),

- engine dummy mount connected to the structure using the existing engine mounts located between frames 28 and 34 inside the engine duct. 


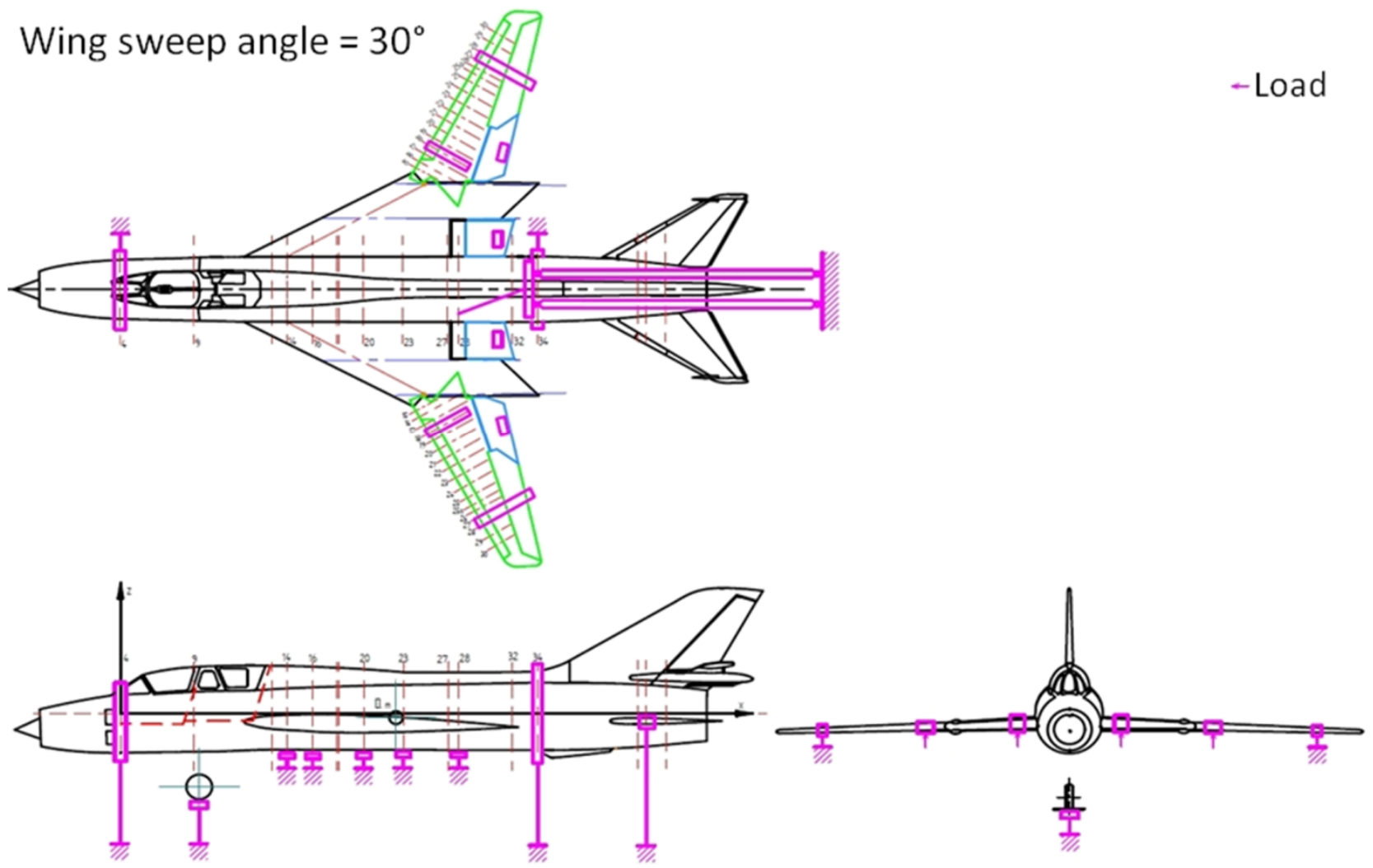

Fig. 4. Test configuration in the flaps test stage

In the third stage, simulating flaps loads, the wing sweep will be set back to 30 degrees. The fixing of the entire aircraft will be done using any necessary fixing points used in the previous stages (Fig. 4 shows possible configuration).

The variable sweep wing clamp has to be removed from rib 23 in order to incline the outer flap. The flaps will be fully extended: the outer flap inclined by 25 degrees along Y axis and the inner flap extended by $200 \mathrm{~mm}$ along $\mathrm{X}$ axis and inclined by 25 degrees along $\mathrm{Y}$ axis.

The flaps will be blocked in the extended position. Loads will be applied to the flaps' lower surfaces by means of pads overlaying several rib/spar sections.

The structure will be loaded by means of 4 actuators:

- two actuators located symmetrically loading the inner flaps,

- two actuators located symmetrically loading the outer flaps.

\section{TEST PREPARATION}

\section{Test specimen preparation}

The test specimen for the FSFT is a withdrawn from service two-seated Su-22 UM3K. Prior to delivery to the test contractor the aircraft structure will be examined and prepared at the Military Aviation Works No 2 in Bydgoszcz. During this stage the following tasks will be carried out:

- removal of the engine,

- removal of the avionics,

- removal of the horizontal stabilizer,

- removal of the canopy,

- partial removal of the fairings (inlet cone, vertical stabilizer antenna), 
- NDI of the wing-fuselage mounts,

- NDI of the main landing gear structure,

- design and manufacturing of the main and front landing gear blockades,

- preparation of the aircraft structure for transportation to the test executioner,

- reinforcing the wing puncture locations on rib 18 by means of composite overlays of thickness of about $6 \mathrm{~mm}$.

Upon the delivery of the test specimen to the test executioner it will be instrumented with the strain measurement array.

\section{Operational Load Monitoring}

In order to determine loads acting on the aircraft structure during operation the Operational Load Monitoring program will be carried out prior to the test start. The selected aircraft structure was instrumented with an array of 40 strain gauges during the overhaul.

The majority of strain gauges will be installed using cyanoacrylate adhesive and instrumented by the test conductor. Selected strain gauges will be installed using epoxy resin. Out of the sensors installed using epoxy resin eight ones will be selected and left on the flight test specimen as a continuous load monitoring system.

An identical strain measuring array will be installed on the fatigue test specimen in order to monitor strains in the aircraft structure during the whole test. The strain measurements carried out by the system will be also used to calibrate the loading system and to monitor the loads exerted on the structure throughout the test. Measurements will be carried out by the test conductor and will be provided to the AFIT as the test goes on.

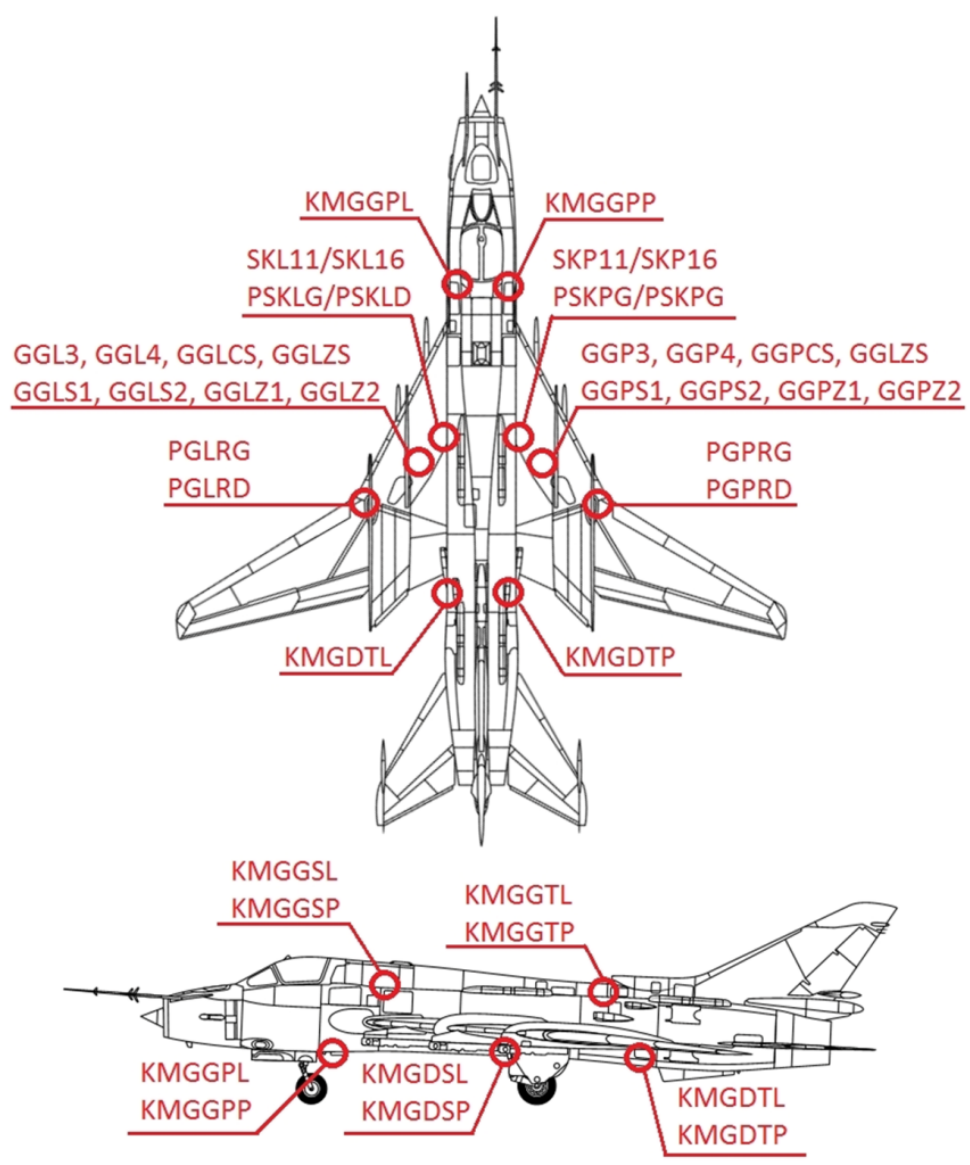

Fig. 5. Location of strain gauges for the OLM program and FSFT 
Locations of the 40 strain gauges are listed below, and shown in Fig. 5:

- wing-fuselage joint section - 8 SGs (4 on each side),

- main wing pivot joint - 4 SG's (2 on each side),

- main landing gear - 8 SG's (4 on each side),

- main landing gear compartment - 10 SG's (5 on each side),

- fuselage $-10 \mathrm{SG}$ 's (2 in each of 5 selected sections).

The strain gauge measurement array has to be calibrated prior to the test start in order to verify the strain with regard to the flight loads. Due to two wing sweep configurations during the test, the calibration has to be divided into two stages and carried out separately before the respective test stages (stage 1 and stage 2 ).

The calibration of the strain gauges system on the aircraft structure should be performed by static loading from zero up to $100 \%$ of the maximum fatigue load of selected load cases. The loading will be applied at 10 load levels at increments of $10 \%$ of applied loads.

The calibration of the loading system should be performed concurrently to validate whether the system works as intended and the desired load levels, adequate to flight load data strains, are achieved.

To identify any possible changes in the structure's behavior during cycling, the Static Checking Test could be performed in defined intervals. Up to 10 such tests will be carried out during the whole test. The Static Checking Test could be performed in the same test set-up as the fatigue test in the same load arrangement up to $100 \%$ fatigue load for a selected load case.

Sampling and recording frequency is expected to be between $25 \mathrm{~Hz}$ and $100 \mathrm{~Hz}$. The most suitable value would be in the range $25 \div 32 \mathrm{~Hz}$.

\section{Load spectrum}

The load spectrum for the test will be defined by the Air Force Institute of Technology (AFIT) after completion of the Operational Load Monitoring program (OLM), and delivered to the test conductor prior to the test start. The load spectrum for the fatigue test will be prepared in the form of a load table specifying force values for all actuators for a given load case. Due to simplifications adopted in the fatigue test preparation it is planned to use the safety factor $\mathrm{k}=4$. For this value, the estimated cycle count and test duration are as follows:

Table 2. Estimation of the fatigue load spectrum number of cycles

\begin{tabular}{|c|c|c|c|c|c|c|}
\hline Load type & $\begin{array}{c}\text { Current value } \\
-\mathrm{a}\end{array}$ & $\begin{array}{l}\text { Value to be } \\
\text { achieved - b }\end{array}$ & $\begin{array}{l}\text { Difference c } \\
\quad=(\mathrm{b}-\mathrm{a})\end{array}$ & $\begin{array}{c}\text { Safety factor } \\
-\mathrm{k}\end{array}$ & $\begin{array}{c}\text { Cycle } \\
\text { number } \\
\text { per unit - e }\end{array}$ & $\begin{array}{c}\text { Load cycles to be } \\
\text { executed } \\
\mathrm{f}=\text { cke }\end{array}$ \\
\hline $\begin{array}{l}\text { Landing } \\
\text { (MLG) }\end{array}$ & 3127 & 6000 & 2873 & 4 & 8/landing & 91936 \\
\hline Taxing & 3127 & 6000 & 2873 & 4 & 4/landing & 45968 \\
\hline Flight & 1583 & 3200 & 1617 & 4 & 100/hour & 646800 \\
\hline $\begin{array}{l}\text { Landing } \\
\text { (flaps) }\end{array}$ & 3127 & 6000 & 2873 & 4 & 5/landing & 57460 \\
\hline & & & & & Total & 842164 \\
\hline
\end{tabular}

The first stage of the test will use the first two rows from Table 2. The number of estimated load cycles to be carried out during the second stage is shown in the third row of Table 2 whereas the last row defines the number of cycles to be carried out in the third test stage (wing flap loads). 
Based on the previous experience, the maximum frequency of load change can be assumed to be approximately $0.5 \mathrm{~Hz}$. With this assumption, the estimated number of cycles can be executed in 1684328 seconds of continuous work:

$$
t=\frac{L}{f}=\frac{842164}{0.5}=1684328[s] \text { for } k=4
$$

Conversed to work days (assuming 8-hour work day), the test itself should take about 59 work days. This estimation includes neither NDI tests stoppages nor any necessary adjustments of the loading system and the structure, nor the time needed to change wings sweep between stages one, two and three.

\section{SUMMARY}

The full scale fatigue test concept presented above was designed in order to verify the assumed number of flight hours and landings for the Su-22 fighter bomber aircraft. The test will be divided into three stages during which different types of operational loads will be exerted on the structure.

As was the case with the SEWST program, there are two aircraft involved in the program in order to prepare the fatigue test load spectrum. Both aircraft were instrumented with identical sets of 40 strain gauges. The strain gauges used on the fatigue test specimen will be also used for test calibration and structural monitoring throughout the test.

The full scale fatigue test of the Su-22 is planned to be started in June 2015. Its completion is scheduled for mid-September 2015. The assumed durability of the aircraft's structure will be proven if no damage is found in the critical structural elements after the completion of all three stages of the test.

\section{REFERENCES}

1. I. A. Anderson, R. G. Parker, Full Scale Fatigue Test of the Pilatus PC9/A trainer aircraft, 20th ICAF Symposium, Bellevue, Washington, USA, 14-16 July 1999

2. L. Molent, S.A. Barter, P. White, B. Dix on, Damage tolerance demonstration testing for the Australian F/A-18, International Journal of Fatigue pp. 1031-1038, 24 May 2008

3. R. S. Rutledge1, D. S. Backman1 and R. J. Hiscocks1, Evaluation, modification and damage tolerance of an in+service aircraft critical area, 25th ICAF Symposium, Rotterdam, 27-29 May 2009

4. S. Klimaszewski, A.Leski, J. Zurek, The Role of AFIT in the Polish Aging Military Aircraft Programs, Proceedings of $7^{\text {th }}$ Joint FAA/DoD/NASA Conference on Aging Aircraft, New Orleans, 9-11 September 2003.

5. Klimaszewski S., Leski A., Dragan K., Kurdelski M. Aircraft Structural Integrity Program of Polish Su-22 Fitter. ASIP 2006 Conference, San Antonio 30.11-06.12.2006. USA, www.asipcon.com 